Energy and Buildings. Special Issue “Advances in Adaptive comfort Modelling and Passive/Hybrid Cooling of buildings”

\title{
Naturally ventilated Double-Skin Façade in Modeling and Experiments
}

Alessandro Dama (*1), Diego Angeli (2), Olena Kalyanova Larsen (3)

(1) Department of Energy - Politecnico di Milano, Via Lambruschini 4, 20156 Milano, Italy

(2) Department of Sciences and Methods for Engineering - University of Modena and Reggio Emilia, Via Amendola 2, 42122 Reggio Emilia, Italy

(3) Department of Civil Engineering - Aalborg University, Thomas Manns Vej 23, 9220 Aalborg, Denmark

(*) corresponding author: alessandro.dama@polimi.it

\section{Abstract}

The modelling activity presented in this work aims at the assessment of a simplified model, named BS model, which was specifically developed for integration of DSF in Building Simulation. The BS model is based on a pressure loop and on an integral approach to the heat transfer along the vertical channel. It considers buoyancy as a function of the average temperature in the channel. The wind action is taken into account by means of wind pressure coefficients $(C p)$ on the façade openings.

The focus of this study is the experimental validation of the modelling "core": the natural ventilation through the DSF. The validation is based on the dataset of the experimental campaign conducted on a DSF test facility, the "Cube”, in Denmark, under IEA ECBCS ANNEX 43/SHC Task 34. Hourly simulations were performed with the BS model for the 15 days of the experimental campaign.

A CFD modelling activity was also carried out on a selection of four cases, extracted from the experimental benchmark and representative of different temperature and pressure boundary conditions.

The results show that the BS model presents a good level of agreement with the experimental data in predicting the mass flow rate and the heat removed by ventilation. Although the two experimental methods used to determine the airflow rate in the DSF cavity produce in many cases divergent results, it was possible to distinguish valid experimental results for comparison with the BS model. This was possible thanks to a 
thorough analysis of the experimental procedure together with the insight provided by the model into the determination of the driving wind and thermal differential pressures. In particular, by selecting only the measurements associated to sufficiently low wind fluctuations in the hourly averaged data, a good degree of correlation was found between the predicted total driving pressure and the flow measurements.

Concerning the four cases investigated also by means of CFD, the agreement between the BS and CFD models is remarkable in terms of outlet temperatures and in the prediction of flow reversal.

Keywords: airflow measurement, building simulation, CFD, double skin façade, experimental validation, natural ventilation, passive cooling, wind pressure coefficients.

\section{NOMENCLATURE}

$\begin{array}{ll}A & \text { area } \\ C d & \text { discharge coefficient } \\ C p & \text { pressure coefficient } \\ C_{p} & \text { specific heat capacity at constant pressure } \\ \text { Dh } & \text { hydraulic diameter } \\ H & \text { channel height } \\ h_{c v} & \text { convective heat exchange coefficient } \\ L & \text { channel width } \\ m & \text { mass flow rate } \\ p & \text { pressure } \\ \text { Re } & \text { Reynolds number } \\ s & \text { channel width } \\ T & \text { temperature } \\ u, v & \text { air velocity } \\ W & \text { wind velocity } \\ \mathrm{X}, \mathrm{y} & \text { channel width } \\ & \text { Cartesian coordinates } \\ & \end{array}$




\begin{tabular}{|c|c|}
\hline \multicolumn{2}{|c|}{ Sub- and superscriptbot } \\
\hline bulk & bulk \\
\hline ext & external \\
\hline inlet & inlet \\
\hline int & internal \\
\hline $\mathrm{m}$ & mean value \\
\hline out & outlet \\
\hline therm & thermal \\
\hline top & top \\
\hline wind & wind \\
\hline
\end{tabular}

\section{Introduction}

Rapid development of glass and frame technology in the past 10 years has brought a lot of advancements to performance, production and installation of window components. This, along with the demand for adaptive building components has led to increasing attention towards the Double-Skin Façade (DSF) concept. In earlier publications [1][2] a lot of positive, but also controversial or negative aspects of double façade performance were discussed. The present situation is by no means different. DSF buildings built in the past and present century continue to suffer from overheating and high cooling demand, whilst engineers and architects continue to look for design tools that can address the performance complexity of such constructions, thus supporting them in the design process towards energy efficient and comfortable buildings.

Discussions of DSF performance continue since 1999 when the first critical report [3] was published. These discussions have led to a number of excellent publications that uncover the veil of unknown which loomed over the field of double-skin façades. However, there is still no breakthrough towards a reliable prediction of double façade performance. The final report of IEA ECBCS ANNEX 43/SHC Task 34 Testing and 
Validation of Building Energy Simulation Tools [4], for example, documents an empirical validation of common building simulation software tools for DSF applications. Main findings of this work are outlined in [5], where it is stated that, for the time being, none of the models appeared to be consistent enough when comparing results of simulations with the experimental data for a naturally ventilated double-skin façade. A number of more recent publications make similar statements, and a knowledge gap within the field of simulation DSF performance is documented. For instance the authors in [6] argue that there remains a need to acquire fundamental principles for design and control, which are quantitatively and qualitatively applicable across a wide range of building types and climatic conditions. Furthermore, in review [7] it is concluded that understanding the complex nature of airflow and heat transfer in a DSF is far from being complete. No suitable tools are available for designing DSF with confidence, taking account of the complicated nature of airflow and heat transfer.

The ultimate challenge with regards to thermal and energy design of buildings with this type of envelope is formulated by Manz and Frank [8], declaring that such a task requires a software tool that can accommodate all of the following three modelling levels: optics of layer sequence, thermodynamics and fluid dynamics. Each of these levels is rather complex as a stand-alone matter, let alone the simulation of façade performance. Until now, many models have been developed with different approaches, each of them targeting one or several modeling levels. Particular attention was paid to thermodynamics and transmission of solar radiation in the DSF cavity within these models. The influence of airflow, though, has not been studied to the same extent. In a recent review [9], it is stated that the study of DSF on naturally ventilated buildings can be considered still at its infancy as most of the research focuses on models for mechanically ventilated cases. Absence of experimental data for naturally ventilated cavities is the main reason for the present state of the art.

The modelling activity presented in this work aims at the experimental assessment of a simplified model, in the following mentioned as BS model, which was specifically developed by one of the authors and implemented in an in-house computational procedure for the DSF integration in Building Simulation.

One of the questions that are being studied and answered here is whether it is possible to predict the mass flow rate and the outlet temperature accurately, in order to evaluate the heat power removed by ventilation 
air from the cavity space. A further objective of this work is to support this study of rather robust model with CFD investigations that provide an insight to specific flow conditions, and help discussing their significance to the model accuracy.

The BS model is based on a pressure loop and on an integral approach to the heat transfer along the vertical channel. It considers buoyancy as a function of the average temperature in the channel. The wind action is taken into account by means of wind pressure coefficients $(C p)$ on the façades openings. A first presentation and experimental assessment of the BS model against measured data was given in [10] and a recent CFD investigation on the model assumptions was given in [11] and [12] . The present study extends both the model validation and the CFD investigation taking into account the dataset of the experimental campaign conducted under IEA ECBCS ANNEX 43/SHC Task 34, whose experimental set up is described in Section 2. Moreover the model version discussed in this paper differs from the one presented in the previous papers for the choices of the surface heat transfer coefficient and for the determination of the wind pressure coefficients, which is described in Section 3.1.

In the CFD model, the differential wind pressure was imposed as a pressure boundary condition in the far field, separating the plena connected to the top and bottom openings. In this way, the combined effect of buoyancy and wind pressure on the flow in the DSF is simulated, based on realistic boundary conditions, derived from experiments. The CFD model is described in Section 3.2

In Section 4 we report and discuss the results of the hourly simulation conducted with the BS model for the 15 days of the experimental campaign. Moreover, four cases, corresponding to four 10-minute time intervals of the experimental benchmark, have been selected, in order to reach earlier stated objectives, but also to support the evaluation of the experimental data. These cases are meant to be representative of four different flow conditions established in the cavity, determined by significantly different thermal and wind conditions. 


\section{Experimental set-up}

\subsection{Test facility}

The Cube is an outdoor full-scale test facility located near the main campus of Aalborg University, Denmark. The Cube was built in the fall of 2005, in the frame of IEA ECBCS ANNEX 43/SHC Task 34. A photo of Southern and Northern façade of the facility is shown in Figure 1. Four separate domains of the building are suited to their specific functions: double skin façade (DSF), experiment room, instrument room and plant room (Figure 2). Key measurements are carried out in the experiment room and DSF, both of them realized as a double-height room. The instrument room is equipped with data loggers and computers and the cooling system is installed in the plant room with the direct access to the outdoor.
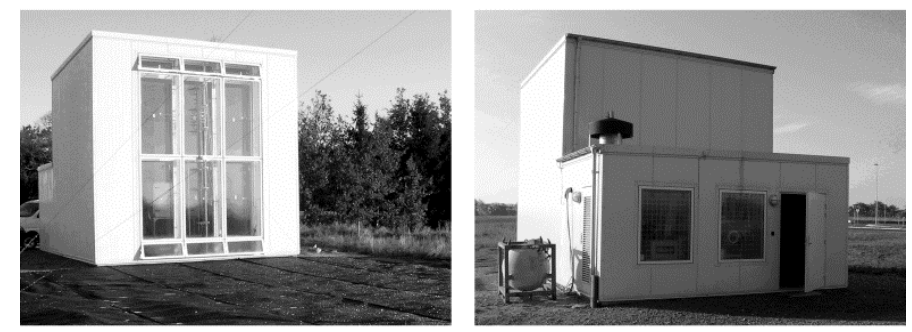

Figure 1. The Cube. Photo of Southern façade (left) and photo of Northern façade (right).

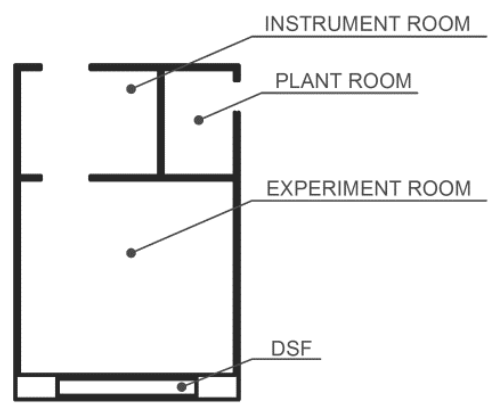

Figure 2. Plan of the Cube. 
The double-skin façade is facing South and consists of an internal double-glazed layer (4-Ar16-4) and a single-glazed exterior layer. The experiments are performed in the external air curtain functioning mode, i.e. with naturally ventilated air cavity. Discharge coefficients for different opening degrees in the experimental set-up are estimated experimentally by pressure difference measurement s across the opening.

The temperature in the experiment room is kept constant at $22^{\circ} \mathrm{C}$, using a ventilation system with a heating and cooling unit. In order to avoid temperature gradients in the experiment room, a recirculating piston flow with an air speed of approximately $0.2 \mathrm{~m} / \mathrm{s}$ is used. This resulted in a typical temperature gradient of approximately $0.02^{\circ} \mathrm{C} / \mathrm{m}$, with a maximum of $0.1^{\circ} \mathrm{C} / \mathrm{m}$. The maximum power on cooling and heating units is $10 \mathrm{~kW}$ and $2 \mathrm{~kW}$ respectively.

All constructions of the test facility are very well insulated and airtight. Specifics of the material properties of constructions in the Cube can be found in [13], as well as glazing properties, spectral properties of finishing in the experiment room and DSF and airtightness characteristics of the test facility.

\subsection{Weather data}

Assembled weather data includes wind speed, wind direction, outdoor air temperature, relative humidity, global and diffuse solar radiation, and atmospheric pressure. Wind velocity and direction is measured in six points above the ground, in order to build a vertical wind velocity profile at the site. The measurement frequency of the wind characteristics is $5 \mathrm{~Hz}$. Total solar radiation intensity is measured on the Southern façade of the Cube, meanwhile total and diffuse solar radiation is measured on the horizontal surface on the roof of the test facility. Pyranometers BF3, Wilhelm Lambrecht-pyranometer, type 1550 and type 1027 were used.

\subsection{Temperature measurements}

Depending on location of the sensor, temperature was registered with two frequencies: every 0.2 second and every 60 seconds. High frequencies were used for the measurement of air temperature in DSF cavity and the temperatures of exhaust air from the cavity, only. 
In [14] it is explained that the presence of direct solar radiation is an essential element for the façade operation, but it can heavily affect measurements of air temperature and may lead to errors of high magnitude using bare thermocouples and even adopting shielding devices. Taking this into consideration, the thermocouples in DSF cavity were protected from the influence of direct solar radiation by a silver coated and ventilated tube; air flow through the tube was ensured by a minifan. Thermocouples were placed in the DSF at six different heights, which are enough to build a vertical temperature gradient.

\subsection{Airflow measurements}

Assessment of the air change rate is of key importance for the evaluation of a double skin façade performance; at the same time the measurement of naturally induced air flow is known for its complexity. These aspects are discussed in [15]. Two methods are used for the air flow measurements in the Cube, namely the velocity profile method and the tracer gas method.

The velocity profile method uses a set of anemometers to measure a velocity profile in the opening. The shape of the determined velocity profile depends on the amount of anemometers installed. Instead of placing the measurement equipment directly at the façade openings, the velocity profile is measured in the DSF cavity, at several levels instead of one, for better accuracy. Hot-sphere anemometers are used in the Cube, as these are proved to be accurate for the expected velocity range and high flow fluctuation, and to be insensitive to solar exposure [16]. Velocity measurements were conducted in the central section of DSF at the six levels indicated by the Roman numbers in Figure. 3, where the horizontal positioning of anemometers in the experimental set-up is illustrated. 


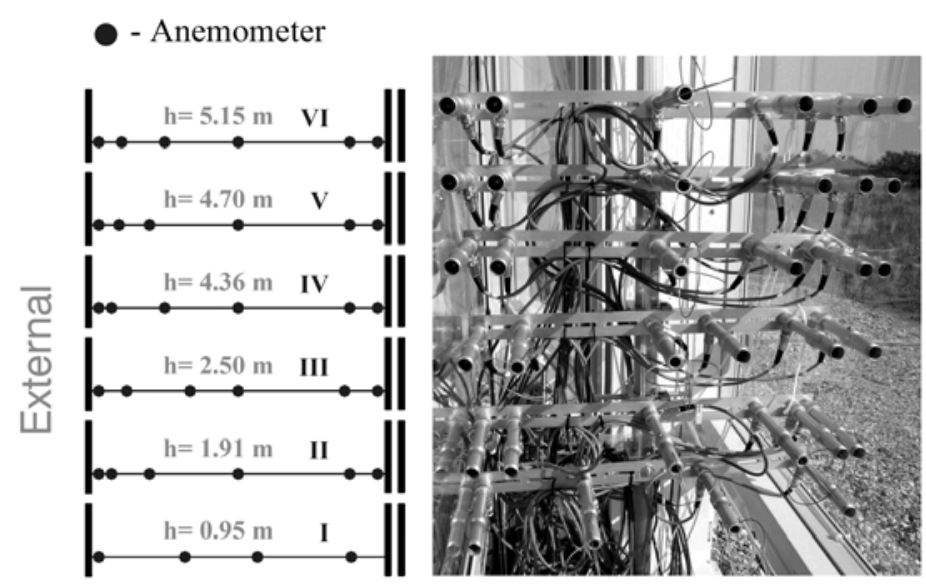

Figure. 3. Positioning of anemometers in the DSF cavity (left). Anemometers in the DSF cavity before they were moved up to their respective heights (right).

In the tracer gas method the measurements are carried out using injection of a tracer gas, namely $\mathrm{CO}_{2}$. The tracer gas is injected at a constant rate and then the concentration response is recorded [17]. According to McWilliams [18] the constant injection method is more appropriate for leaky spaces where the gas would be quickly ventilated from the space; hence, it has been deemed as suitable for DSF. Carbon dioxide is released in the lower part of the double skin façade cavity. An even distribution of the tracer gas along the DSF cavity is ensured by injecting it through a perforated tube. Samples of the tracer gas dilution are taken in 12 points at the top of the DSF cavity.

The overall uncertainty of equipment used in the experimental set-up is summarized in Table 1.

\begin{tabular}{|l|l|}
\hline Temperature & \multicolumn{1}{|c|}{$+-0.07^{\circ} \mathrm{C}$} \\
HELIOS datalogger & $+/-0.14^{\circ} \mathrm{C}$ \\
HBM datalogger & \\
\hline Solar radiation & $+/-10 \%$ \\
Diffuse on horizontal surface & $+/-2 \%$ \\
Total on horizontal surface & $+/-3 \%$ \\
Total on vertical surface ( DSF) & \\
\hline
\end{tabular}




\begin{tabular}{|l|l|}
\hline Wind speed & $\begin{array}{l}+/-1 \% \\
+/-4 \%\end{array}$ \\
3D ultrasonic anemometers & $+/-3^{\circ}$ \\
2D anemometers & $+/-3^{\circ}$ \\
\hline Wind direction & \\
2D anemometers & $+/-0.05 \mathrm{~m} / \mathrm{s}$ \\
\hline Air velocities & $+/-10 \mathrm{ppm}$ \\
Hot sphere anemometers & $+/-10 \mathrm{ppm}$ \\
\hline Concentration of CO2 & \\
\hline In the DSF (BINOS) & \\
In the outdoor air (URAS) & \\
\hline
\end{tabular}

Table 1. Measurement uncertainty of equipment used in the experimental set-up.

\section{Models}

\subsection{BS model}

The BS model of the DSF is based on a differential formulation of the energy balance along the ventilated channel and on a pressure loop inside and outside the DSF, which are respectively devoted to describe the thermal and the fluid-dynamic problem. They are solved together by means of simple iterations on the volume averaged temperature and on the bulk velocity in the channel.

In this study we focus on the convective problem and the mass flow rate inside the channel, which is known to be the most critical issue for this kind of models in naturally ventilated DSF. Therefore the thermal boundary conditions (input for the BS model) are given by the glazing surface temperatures of the DSF and by the external air temperature, derived from the experimental data.

We report in the following the main equations of the model: 
- Energy balance in the ventilated cavity (also adopted in EN 13362-2 standard):

$$
\left\{\begin{array}{c}
{\left[h_{c v 1}\left(T_{w 1}-T(y)\right)+h_{c v 2}\left(T_{w 2}-T(y)\right)\right] L d y=\dot{m} c_{p} d T} \\
T(0)=T_{\text {inlet }} \quad 0 \leq y \leq H
\end{array} \Rightarrow T(y)=\bar{T}_{w}+\left(T_{\text {inlet }}-\bar{T}_{w}\right) e^{-k y} \quad\left\{\begin{array}{c}
\bar{T}_{w} \equiv \frac{h_{c v 1} T_{w 1}+h_{c v 2} T_{w 2}}{h_{c v 1}+h_{c v 2}} \\
k \equiv \frac{\left(h_{c v 1}+h_{c v 2}\right)}{s v_{b u k} \rho_{\text {int }} c_{p}}
\end{array}\right.\right.
$$

Where for the convective heat transfer coefficient here we use the Mc Adams’s correlation

$$
h_{c v 1}=h_{c v 2}=5.62+3.9 \mathrm{v}_{\text {bulk }}
$$

and the inlet temperature is corrected from the outside temperature taking into account the preheating effect due to the frame basement as formerly suggested by [19] and implemented in [12]

- $\quad$ Pressure loop (see Figure 6.a):

$$
\Delta p_{\text {therm }}+\Delta p_{\text {wind }}=\rho_{\text {in }} \frac{1}{2}\left(\frac{v_{\text {in }}}{C d_{\text {bot }}}\right)^{2}+\rho_{\text {int }} \frac{v_{\text {bulk }}^{2}}{2} \frac{\Delta z}{D h} \xi(R e)+\rho_{\text {out }} \frac{1}{2}\left(\frac{v_{\text {out }}}{C d_{\text {top }}}\right)^{2}
$$

Where

- $\quad$ the wind differential pressure in given by

$$
\Delta p_{\text {wind }}=\rho_{\text {ext }} \frac{w_{H}^{2}}{2} \Delta C p=\rho_{\text {ext }} \frac{w_{H}^{2}}{2}\left(C p_{\text {bot }}-C p_{\text {top }}\right)
$$

- $\quad$ the buoyancy pressure in given by

$$
\Delta p_{\text {therm }}=\left(\rho_{\text {ext }}-\rho_{\text {int }}\right) g \Delta z
$$

- the inlet and outlet friction terms have been evaluated adopting Discharge Coefficients given by the experimental characterization of the bottom and top openings: $C d_{b o t}=0.65$ and $C d_{\text {top }}=0.72$

- the friction along the vertical channel was calculated according to the correlation of Colebrook and White (1937).

The wind pressure coefficients have been evaluated using the wind pressure database of the Tokyo Polytechnic University [20] for "isolated low rise buildings without eaves”. The point pressure measurements from wind tunnel tests have been averaged in time and position along the top and bottom openings of the DSF. The resulting profiles, as a function of the wind attack angle, are reported in Fig. 4. The wind velocity at the roof height $(H=6 \mathrm{~m})$ was calculated from the reference value measured at $10 \mathrm{~m}$ height according to the following relation with $\alpha=0.2$. This value corresponds to terrain category III, according to 
the classification given in [21] and reproduces the same experimental profile obtained in the wind tunnel test for the derivation of the $C p$ pressure coefficients.

$$
w_{h}=\left(\frac{h}{h_{r e f}}\right)^{\alpha} w_{r e f}
$$

Approximating the air density in the right term of Equation 4 to the external value we get the following implicit equation for the bulk velocity and its Reynolds Number, that can be solved iteratively.

$$
v_{\text {bulk }}^{2}=\frac{2 \Delta p_{\text {tot }} / \rho_{\text {ext }}}{\left(\frac{A_{\text {int }}}{A_{\text {bot }} C d_{\text {bot }}}\right)^{2}+\frac{\Delta z}{D h} \xi(R e)+\left(\frac{A_{\text {int }}}{A_{\text {top }} C d_{\text {top }}}\right)^{2}}
$$

where the total driving pressure is given by

$$
\Delta p_{\text {tot }} \equiv \Delta p_{\text {therm }}+\Delta p_{\text {wind }}
$$

From Equation 7 we can also define an equivalent discharge coefficient for the ventilated cavity, which takes into account all the friction losses, and an ideal velocity, $v^{*}$, which is representative of the driving forces, i.e. of the boundary conditions:

$$
\begin{gathered}
v^{*} \equiv \sqrt[2]{2 \Delta p_{\text {tot }} / \rho_{\text {ext }}} \\
C d_{\text {equiv. }} \equiv \frac{v_{\text {bulk }}}{v^{*}}=\frac{1}{\sqrt[2]{\left(\frac{A_{\text {int }}}{A_{\text {bot }} C d_{\text {bot }}}\right)^{2}+\frac{\Delta z}{D h} \xi(R e)+\left(\frac{A_{\text {int }}}{A_{\text {top }} C d_{\text {top }}}\right)^{2}}}
\end{gathered}
$$

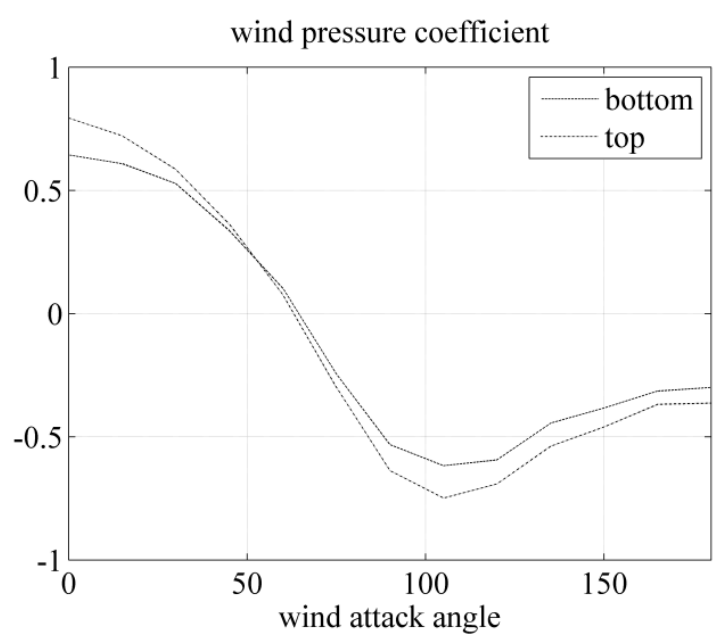

Figure 4 Wind pressure coefficients calculated from the TPU database 


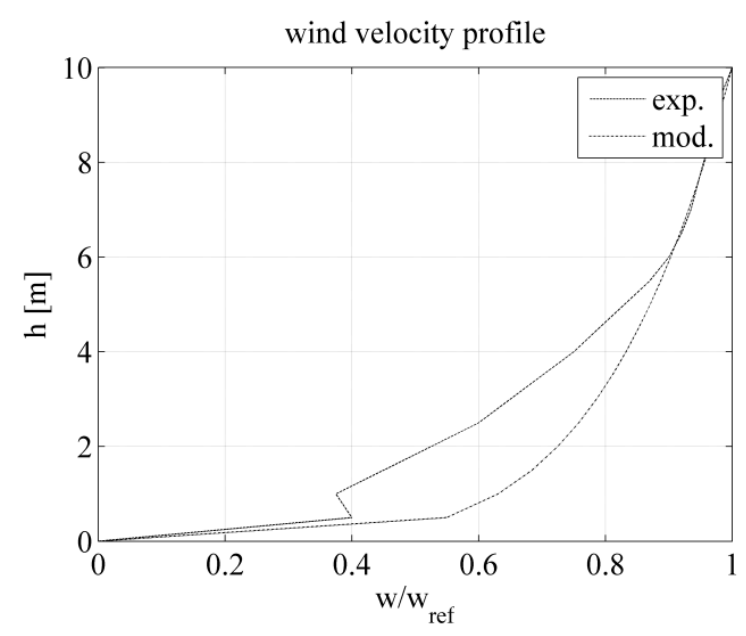

Figure 5 Wind velocity profiles. Measured values vs. model assumption

\subsection{CFD model}

(a)

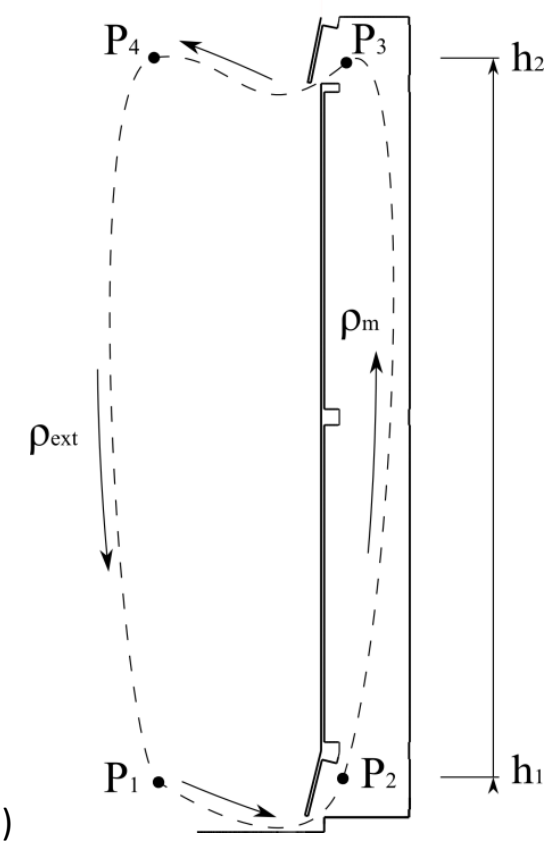

(b)

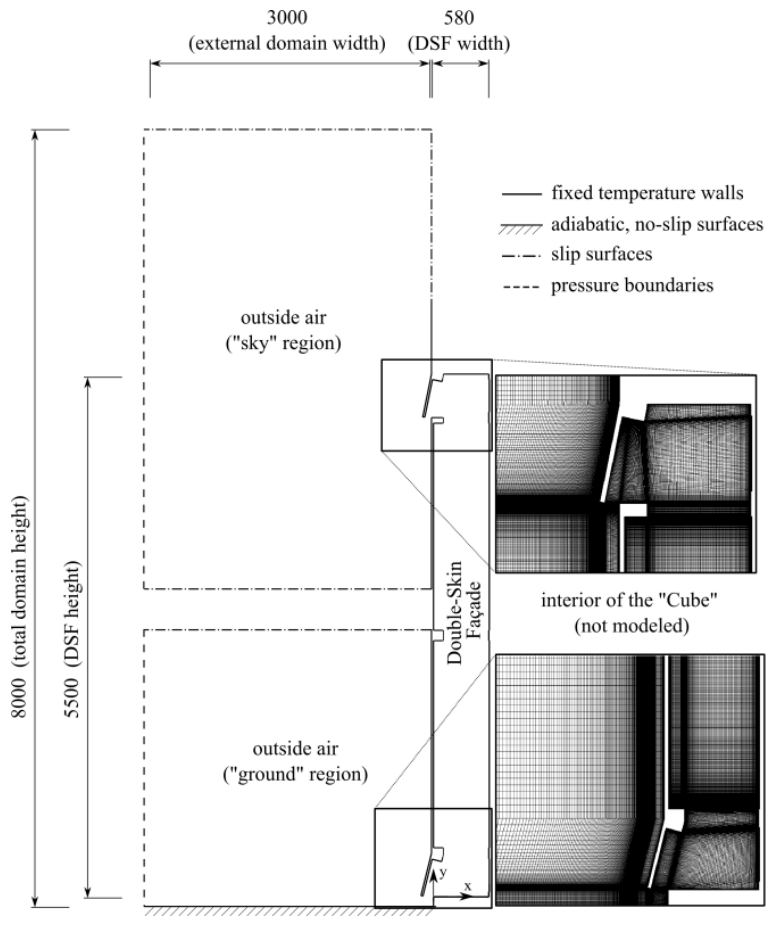

Figure 6: (a) pressure loop scheme in the BS model; (b) CFD domain and details of the computational grid - main dimensions are reported, in $\mathrm{mm}$. 
Two-dimensional, unsteady Reynolds-Averaged Navier-Stokes (U-RANS) numerical simulations have also been performed in the frame of the present work, with the purpose of drawing a comparison between CFD results and both the outcomes of the analytical model described above and the experimental dataset at hand. The choice of RANS modelling to tackle the problem of natural ventilation in a system like the DSF investigated here, involving both pressure and buoyancy effects, is subjected to inevitable limitations, given the high sensitivity to thermal boundary conditions, the presence of zones of laminar-turbulent transition, and the possible occurrence of metastable states in the real-world case. All these features are not always reproducible by means of the Reynolds-Averaged equations, even though an unsteady approach is followed (as in the present case). However, the resort to high fidelity simulations (Large Eddy Simulation or even Direct Numerical Simulation) would have gone far beyond the scope of the present work, and is envisaged for future developments.

Four cases, corresponding to four 10-minute time intervals of the experimental benchmark, have been considered, as detailed in the results section. These are meant to be representative of four different flow conditions establishing in the cavity, determined by very different thermal and wind conditions.

The calculations have been carried out by means of a finite-volume solver based on the open source OpenFOAM ${ }^{\circledR}$ computational toolbox [22], implementing the RANS and energy conservation equations governing non-isothermal, turbulent flow. The Oberbeck-Boussinesq approximation has been enforced [23], all fluid properties being taken as constant except for density in the buoyancy term. As in previous analyses performed on the same case, [12], turbulence has been modelled by means of the SST $k$ - $\omega$ model [24]. Turbulent heat diffusivity has been determined by means of the Reynolds analogy, assuming a constant value of the turbulent Prandtl number $P r_{\mathrm{t}}=0.85$.

The 2D computational domain considered in the simulations is schematized in Figure 6b. In the computational model, the cross section of the double-skin façade of the "Cube" has been reproduced in detail, including the outline of the window framing. The domain boundaries have been subdivided as in Figure $6 \mathrm{~b}$, and uniform temperature conditions have been imposed at all glazed surfaces of the façade, as well as at its ground and ceiling. Such temperature values are directly taken from the experimental data. 
Hence, the real physics of radiation and of conjugate heat transfer between the glazing and frames and the surrounding air, has been substituted by constant wall temperatures. Albeit strong, such an approximation is deemed to be sufficiently realistic for the scope of the present work. It is only mentioned here that different temperature values have been imposed on the lower and upper part of both the internal and external glass of the DSF, in order to better reproduce the vertical wall temperature gradient in the cavity, whilst staying adherent to the available data. These temperature values will not be reported in the following, for the sake of conciseness. Only their average (as used in the BS model) will be included in the graphs as a reference.

The outer atmosphere has been modelled as a large plenum, partitioned in two different subdomains, so as to enforce a pressure difference between the bottom and the top openings, thus simulating the effect of wind pressure. The values of the imposed $\Delta p_{\text {wind }}$ for the different cases are the same employed in the BS model for the corresponding time interval. Additional "virtual" boundaries have been created in the form of slip walls, i.e. surfaces of zero shear-stress, at which only the tangential flow component is nonzero. Such boundaries do not correspond to any physical surface, but they have been included in the model in order to stabilize the convergence of the calculations, given the presence of a double pressure boundary. Due to the presence of such surfaces, the prediction of the flow field outside of the DSF is expected to partially deviate from reality; nevertheless, the flow and temperature fields inside the DSF are expected not to be influenced significantly by these artificial boundaries. Furthermore, the zero shear-stress condition ensures that no additional viscous losses are introduced in the computation.

Details of the block-structured computational grid employed are displayed in Figure 6.b. The total number of quadrilateral mesh elements amounts to 300000. Near-wall sizing $(\Delta y=0.5 \mathrm{~mm}$ everywhere along the wallnormal direction) has been chosen so as to avoid the resort to wall functions and, hence, to reproduce the mean features of the diffusive sub-layers [12]. Second-order schemes were adopted for both time and space discretization. A hybrid PISO-SIMPLE algorithm ([25], [26]) has been employed for the de-coupling of pressure and velocity in the transient solution. Such a practice allows for the simulation of timesteps with a Courant number larger than the typical threshold $\mathrm{Co}=1$. Here, a maximum value $\mathrm{Co}=5$ has been enforced. The simulations have been protracted until a statistically steady flow has been attained. 50 snapshots per case have been employed to calculate the mean fields, for a total of approximately 10 flow-through times. 


\section{Results and discussion}

In this section we present the results of two set of simulations. The first one was performed on hourly basis with the BS model, for the entire period of the experimental campaign, 15 days. The second set involves only four selected cases, which correspond to four measurement intervals of ten minutes extracted from the same experimental campaign.

A key issue was the determination of the wind differential pressure at the openings, which was used as pressure boundary condition also for the CFD investigation. The wind differential pressures were evaluated based on wind magnitude and direction measurements for every ten minutes and then averaged to give the hourly boundary conditions.

A modified Coefficient of Variation (similar to the relative standard deviation) has been introduced to quantify in each hour the dispersion of the wind differential pressures $\Delta p_{\text {wind }}$ calculated for every 10 minutes, here modified with respect to the total driving pressure instead of the mean wind differential pressure.

$$
\begin{aligned}
& \Delta p_{\text {wind-60min }}=\operatorname{mean}\left(\Delta p_{\text {wind-10min }}\right) \\
& C V_{\text {wind }} \equiv \operatorname{std}\left(\Delta p_{\text {wind-10min }}\right) /\left|\operatorname{mean}\left(\Delta p_{\text {wind-10min }}\right)+\Delta p_{\text {therm }}\right|
\end{aligned}
$$

\subsection{BS model: hourly simulation versus experimental data}

The BS model validation is based on the prediction of the mass flow rate and the outlet temperature, from which we can evaluate the heat power removed by ventilation through the DSF, which is the most important quantity from the point of view of passive cooling applications

$$
\dot{Q}_{V}=\dot{m} c_{p}\left(T_{\text {out }}-T_{\text {ext }}\right)
$$

The experimental outlet temperature used for comparisons was the one measured at a height $y=5.5 \mathrm{~m}$ : such a choice is valid only for upward flows, and not in case of reversed flows. Figure 7 shows the inlet and outlet bulk temperatures predicted by the BS model and the point measurements at $\mathrm{y}=5.5 \mathrm{~m}$ (only when an 
upward flow is predicted). Figure 8 reports the volume flow rates measured according to the two methods described in Section 2 and the BS model predictions. For the velocity profile method, the calculation of the volume flow rate was performed by applying second-order quadrature to the experimental velocity data measured at $1.91 \mathrm{~m}$ and at $2.5 \mathrm{~m}$ height (profiles II and III, respectively), and, when both profiles were available, the lesser result was chosen.

By looking at Figure 8 it can be observed that all the large flow rate peaks of volume flow rate, as detected by the tracer gas method, are localized when the modelled wind and total differential pressure are very high or when the total differential pressure is negative (see days from $6^{\text {th }}$ to $10^{\text {th }}$ ).

In the first cases (days $7^{\text {th }}$ and $8^{\text {th }}$ ) the model predictions are in good accordance with the volume flow rate measured with the velocity profile method. In these two days the tracer gas method can be affected by washout at the openings due to the combination of high wind speeds and a wind direction orthogonal to the DSF. In the second cases (days $6^{\text {th }}$, $9^{\text {th }}$ and $10^{\text {th }}$ ) the prediction of flow reversal is coherent with the possibility of "false detection" from the tracer gas method. Indeed the $\mathrm{CO}_{2}$ is emitted always at the bottom and measured at the top; instead, when the air flow is directed downwards, a poor concentration of $\mathrm{CO}_{2}$ at the top can be falsely ascribed to a very high mass flow rate upwards.

For modest wind differential pressures and buoyancy driven flows, the modelled flow rate is in good agreement with the experimental values from tracer gas method (see days from $11^{\text {th }}$ to $15^{\text {th }}$ ). A possible overestimation of the velocity profile method can be a consequence of the fact that the anemometers measure the velocity magnitude and not its vertical component.

In Tables 2 and 3 we have daily integrated the two main BS model outputs, volume flow rate and heat removed. The integration is limited to daylight hours in order to increase the significance of the results in relation with the typical applications of the DSF, and split in two sets: for predicted upward flows and downward flows, respectively.

The results in Table 2 show that for the predicted heat removed by ventilation is in very good agreement with experimental values calculated from the tracer gas method in days $3^{\text {rd }}, 4^{\text {th }}, 5^{\text {th }}, 14^{\text {th }}$ and $15^{\text {th }}$, with discrepancies below $10 \%$ and acceptable in days $1^{\text {st }}, 12^{\text {th }}$ and $13^{\text {th }}$, in which the relative errors are respectively $-22 \%,-32 \%$ and $-11 \%$. 
In the other days the model predictions are better aligned with the experimental values calculated from measurements with velocity profile method. In terms of heat flow in days $6^{\text {th }}$ and $7^{\text {th }}$, the discrepancies are below $10 \%$ and in days $2^{\text {nd }}, 8^{\text {th }}$ and $9^{\text {th }}$ the relative errors are around $-30 \%$.

Results in Table 3 show a fair agreement between the model prediction of the flow rate and the measurements with the velocity profile methods also for the predicted reversal flows.

In order to analyze the degree of correlation between the total differential pressure predicted by the model and the measurements of volume flow rates with the two aforementioned methods, a selection criterion was introduced in order to exclude the hourly data effected by high wind fluctuations in the calculation of the mean total driving pressure. For this purpose only the measurement data corresponding to predicted upwards flow and with $C V$ wind $<25 \%$ (as defined in Equation 12) have been considered. Figure 9 reports the bulk velocities (from BS model, anemometers and tracer gas measurements), and the "ideal” velocity defined by Equation (9), which represents the total driving pressure predicted by the BS model, adopting the abovedefined filtering criterion. A linear fitting can be drawn for each experimental method. The slope of the interpolation line for the BS model represents the equivalent Discharge Coefficient, defined in Equation 10. In Figure 9. It can be seen that the slope of the fitting line for the velocity profile method is very close to the BS model prediction. The numerical results of the fitting are reported in Table 4. The higher estimation of the tracer gas method is mainly due to a group of points in which the total and wind pressure are very high and the wind is almost orthogonal to the façades. It has already been pointed out that this condition might cause wash-out effects that can affect the accuracy of tracer gas method.

Table 2. Mass flow rate and heat removed (per unit length), comparison between BS model and measurements. Values are integrated over the daylight hours in which the flow is predicted upwards.

\begin{tabular}{|c|c|c|c|c|c|c|c|c|c|c|c|}
\hline \multirow{2}{*}{$\begin{array}{l}\text { Day } \\
\text { (Oct.) }\end{array}$} & \multirow{2}{*}{$\begin{array}{l}\mathbf{N}^{\circ} \text { of } \\
\text { hours }\end{array}$} & \multicolumn{3}{|c|}{ Vol. flow rate $\left[\mathrm{m}^{3} / \mathrm{s} / \mathrm{m}\right]$} & \multicolumn{2}{|c|}{$(\bmod -\exp ) / \exp$} & \multicolumn{3}{|c|}{ Heat removed [W/m] } & \multicolumn{2}{|c|}{$(\bmod -\exp ) / \exp$} \\
\hline & & Model & Ane. & $\mathrm{CO} 2$ & Ane. & $\mathrm{CO} 2$ & Model & Ane. & $\mathrm{CO} 2$ & Ane. & $\mathrm{CO} 2$ \\
\hline 1 & 10 & 0.34 & 0.62 & 0.58 & $-45 \%$ & $-40 \%$ & 3026 & 4642 & 3902 & $-35 \%$ & $-22 \%$ \\
\hline
\end{tabular}




\begin{tabular}{|r|r|r|r|r|r|r|r|r|r|r|r|}
\hline 2 & 4 & 0.12 & 0.27 & 0.31 & $-55 \%$ & $-60 \%$ & 765 & 1097 & 1206 & $-30 \%$ & $-37 \%$ \\
\hline 3 & 9 & 0.40 & 0.50 & 0.44 & $-19 \%$ & $-8 \%$ & 1907 & 2167 & 1804 & $-12 \%$ & $6 \%$ \\
\hline 4 & 9 & 0.71 & 0.60 & 0.53 & $18 \%$ & $34 \%$ & 2015 & 2384 & 1994 & $-15 \%$ & $1 \%$ \\
\hline 5 & 9 & 0.62 & 0.89 & 0.57 & $-30 \%$ & $9 \%$ & 4136 & 6425 & 4124 & $-36 \%$ & $0 \%$ \\
\hline 7 & 7 & 0.73 & 0.48 & 1.07 & $-52 \%$ & $-78 \%$ & 1039 & 1106 & 2431 & $-6 \%$ & $-57 \%$ \\
\hline 8 & 10 & 1.49 & 1.37 & 1.61 & $9 \%$ & $-7 \%$ & 4342 & 6197 & 6584 & $-30 \%$ & $-34 \%$ \\
\hline 9 & 3 & 0.08 & 0.18 & 0.24 & $-53 \%$ & $-66 \%$ & 904 & 1273 & 1674 & $-29 \%$ & $-46 \%$ \\
\hline 10 & 0 & & & & & & & & & & \\
\hline 11 & 0 & & & & & & & & & & \\
\hline 12 & 7 & 0.40 & 0.46 & 0.51 & $-14 \%$ & $-22 \%$ & 484 & 653 & 715 & $-26 \%$ & $-32 \%$ \\
\hline 13 & 6 & 0.42 & 0.62 & 0.36 & $-32 \%$ & $18 \%$ & 3513 & 6840 & 3958 & $-49 \%$ & $-11 \%$ \\
\hline 14 & 6 & 0.38 & 0.63 & 0.34 & $-41 \%$ & $12 \%$ & 3131 & 5953 & 3279 & $-47 \%$ & $-5 \%$ \\
\hline 15 & 8 & 0.51 & 0.65 & 0.43 & $-21 \%$ & $21 \%$ & 4146 & 5744 & 4214 & $-28 \%$ & $-2 \%$ \\
\hline TOT & $\mathbf{9 4}$ & $\mathbf{6 . 4 5}$ & $\mathbf{8 . 0 4}$ & $\mathbf{8 . 4 4}$ & $-20 \%$ & $-24 \%$ & $\mathbf{3 1 6 8 8}$ & $\mathbf{4 6 ~ 7 5 9}$ & $\mathbf{4 0 ~ 1 8 7}$ & $-\mathbf{3 2 \%}$ & $-\mathbf{2 1 \%}$ \\
\hline
\end{tabular}

Table 3. As in Table A3 but for the daylight hours in which the flow is predicted downwards

\begin{tabular}{|c|c|l|l|l|}
\hline $\begin{array}{l}\text { Day } \\
\text { (Oct.) }\end{array}$ & $\begin{array}{l}\text { No of } \\
\text { hours }\end{array}$ & \multicolumn{2}{l|}{\begin{tabular}{l}
\multicolumn{2}{l|}{ Vol. flow rate } \\
{$\left[\mathbf{m}^{3} / \mathbf{s} / \mathbf{m}\right]$}
\end{tabular}} & $\begin{array}{l}\text { (mod- } \\
\text { exp)/exp }\end{array}$ \\
\hline & & Model & Ane. & Ane. \\
\hline 1 & 0 & & & \\
\hline 2 & 5 & 0.32 & 0.34 & $-7 \%$ \\
\hline 3 & 0 & & & \\
\hline 4 & 0 & & & \\
\hline 5 & 0 & & & \\
\hline
\end{tabular}




\begin{tabular}{|c|c|c|c|c|}
\hline 6 & 3 & 0.12 & 0.14 & $-15 \%$ \\
\hline 7 & 2 & 0.15 & 0.13 & $16 \%$ \\
\hline 8 & 0 & & & \\
\hline 9 & 5 & 0.23 & 0.36 & $-38 \%$ \\
\hline 10 & 0 & & & \\
\hline 11 & 0 & & & \\
\hline 12 & 0 & & & \\
\hline 13 & 0 & & & \\
\hline 14 & 0 & & & \\
\hline 15 & 0 & & & \\
\hline Tot. & $\mathbf{1 5}$ & $\mathbf{0 . 8 2}$ & $\mathbf{0 . 9 8}$ & $\mathbf{- 1 6 \%}$ \\
\hline
\end{tabular}

Air temperatures

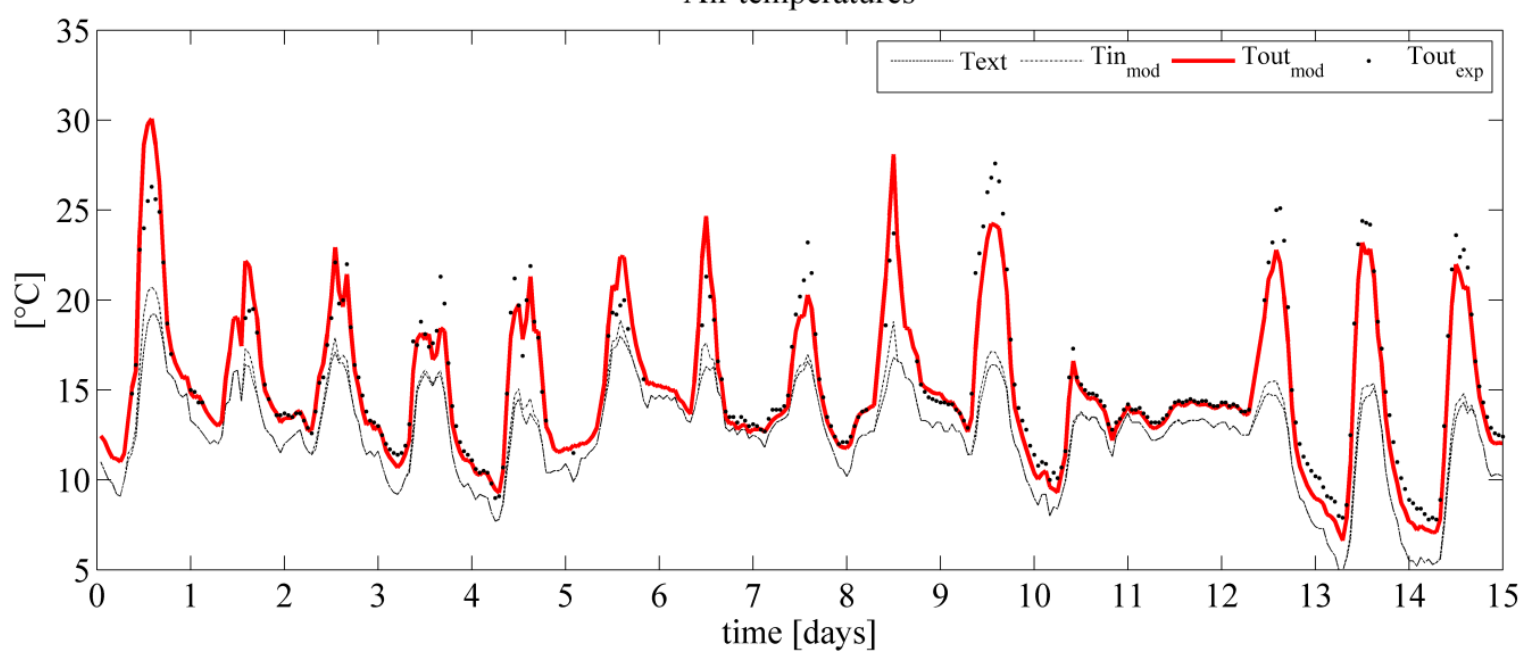

Figure 7 Outlet temperatures, BS model versus measurements 


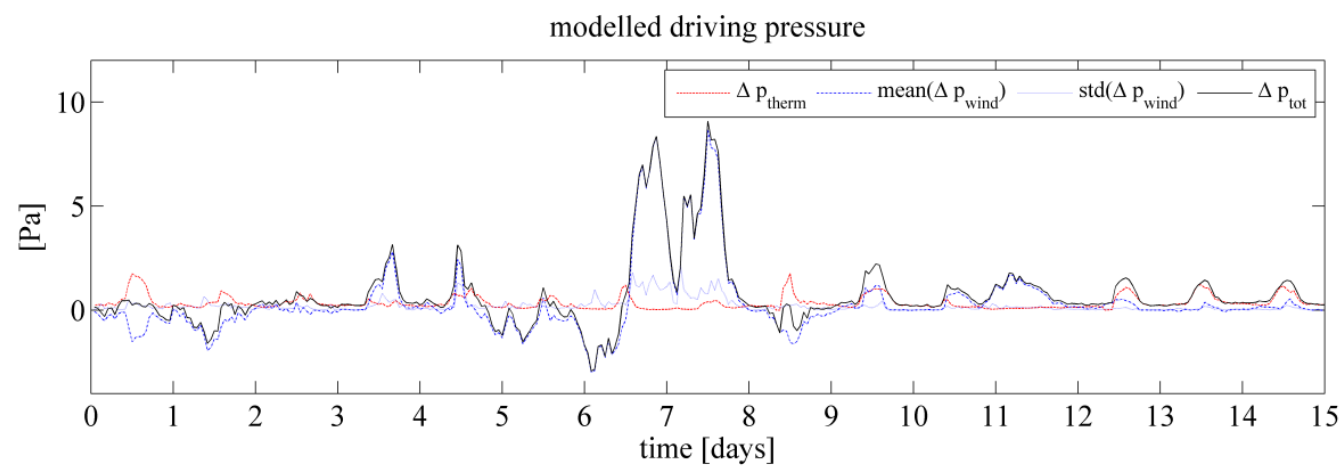

Volume flow rate

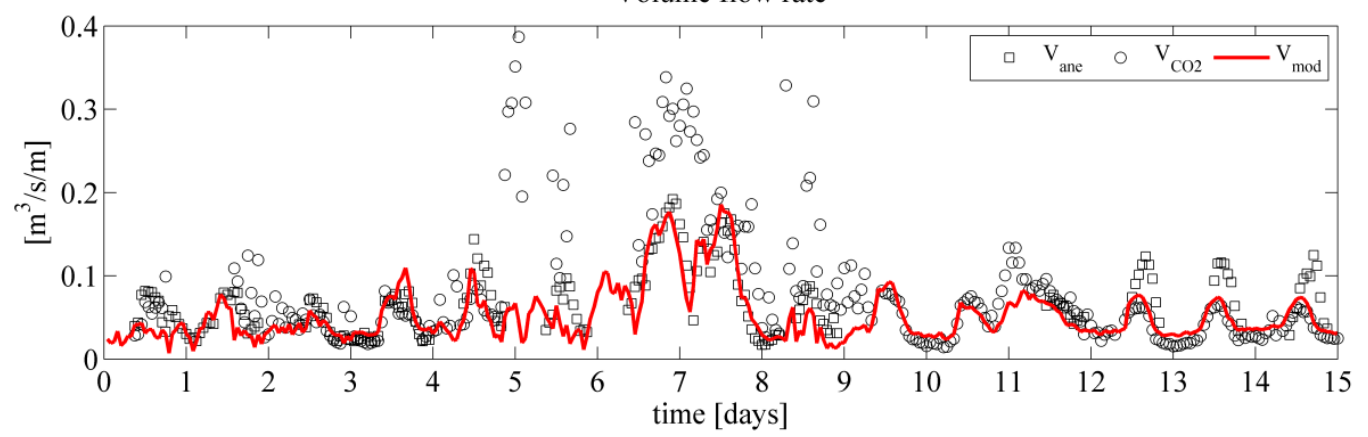

Figure 8 Volume flow rates, BS model versus measurements, and differential pressures

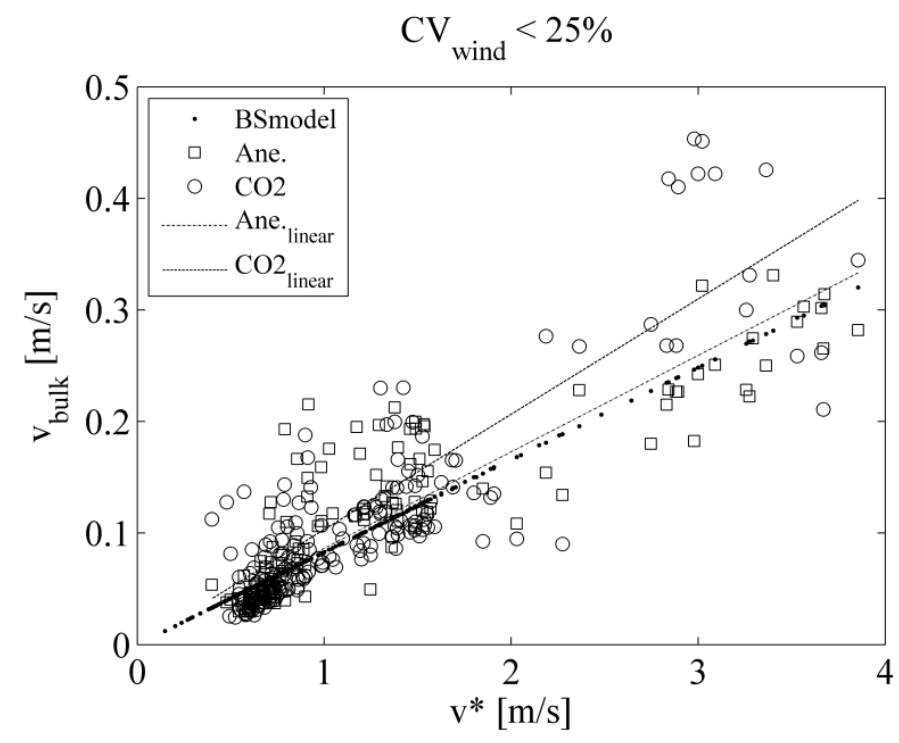

Figure 9 Correlation between the bulk velocities (from BS model, anemometer and tracer gas measurements) and the “ideal” velocity (defined by Equation 9), for predicted upwards flow and measurements data that fulfill the criterion $C V_{\text {wind }}<25 \%$. For the BS model the slope of the interpolation line represents the equivalent Discharge Coefficient. 
Table 4 Correlation indices and coefficients of the linear fitting in Figure 9

\begin{tabular}{|l|l|l|l|}
\hline Model/Exp. & Cd_equiv & $95 \%$ confidence & $\mathrm{R}^{2}$ \\
\hline BS model & 0.083 & & \\
\hline Velocity profile & 0.086 & $0.082-0.091$ & 0.723 \\
\hline Tracer gas & 0.103 & $0.098-0.109$ & 0.712 \\
\hline
\end{tabular}

\subsection{CFD investigation versus BS model and measurements}

Four cases, corresponding to four 10-minute time intervals of the experimental benchmark, have been selected, in order to perform a cross comparison of CFD, BS model results and measurements. These are meant to be representative of four different flow conditions establishing in the cavity, in virtue of very diverse thermal and wind boundary conditions.

In order to the select different conditions in terms of buoyancy potential we defined the temperature differential potential for buoyancy as

$$
\Delta T^{*} \equiv\left(T_{e i}+T_{i e}\right) / 2-T_{e x t}
$$

Table 5 reports the selected boundary conditions and a schematic description in given here:

- Case A: buoyancy is dominant, but counterbalanced by downward wind pressure

- Case B: downward wind pressure is dominant against weak buoyancy and produces flow reversal

- Case C: strong upward wind differential pressure and weak buoyancy

- Case D: buoyancy is supported by a moderate upward wind differential pressure 
Table 5 Case studies selection for the CFD model. Main temperature and pressure boundary conditions

\begin{tabular}{|l|l|l|l|l|l|l|l|l|}
\hline Case & Date \& time & $\begin{array}{l}\text { Ta_ext } \\
{\left[{ }^{\circ} \mathrm{C}\right]}\end{array}$ & $\begin{array}{l}\text { Tei } \\
{\left[{ }^{\circ} \mathrm{C}\right]}\end{array}$ & $\begin{array}{l}\text { Tie } \\
{\left[{ }^{\circ} \mathrm{C}\right]}\end{array}$ & $\begin{array}{l}\Delta T^{*} \\
{\left[{ }^{\circ} \mathrm{C}\right]}\end{array}$ & $\begin{array}{l}\text { wind_vel. } \\
{[\mathrm{m} / \mathrm{s}]}\end{array}$ & $\begin{array}{l}\text { wind_dir. } \\
\left(0^{\circ} \text { Nord }\right)\end{array}$ & $\begin{array}{l}d p \_w i n d \\
{[\mathrm{~Pa}]}\end{array}$ \\
\hline $\boldsymbol{A}$ & Oct.1, 13:40-13:50 & 19.0 & 30.2 & 32.7 & 12.4 & 4.2 & $183^{\circ}$ & -1.23 \\
\hline $\boldsymbol{B}$ & Oct.2, 12:00-12:10 & 13.4 & 16.5 & 19.9 & 4.8 & 4.3 & $180^{\circ}$ & -1.38 \\
\hline $\boldsymbol{C}$ & Oct.8, 15:30-15:40 & 15.1 & 18.9 & 21.2 & 4.9 & 9.2 & $278^{\circ}$ & 5.00 \\
\hline $\boldsymbol{D}$ & Oct.13, 13:10-13:20 & 14.6 & 28.6 & 29.5 & 14.5 & 4.3 & $107^{\circ}$ & 0.47 \\
\hline
\end{tabular}

Table 6 BS model and CFD results vs measurements

\begin{tabular}{|c|c|c|c|c|c|c|c|}
\hline & \multicolumn{3}{|c|}{ Outlet - external Temperature [ $\left.{ }^{\circ} \mathrm{C}\right]$} & \multicolumn{2}{c|}{ Volume flow rate per unit length [m $3 / \mathrm{s} / \mathrm{m}]$} \\
\hline & BS model & CFD & Measurem. & BS model & CFD & vel. profile \\
(module) & tracer gas \\
\hline $\boldsymbol{A}$ & 10.5 & 10.9 & 7.2 & 0.034 & 0.013 & 0.077 & 0.060 \\
\hline $\boldsymbol{B}$ & 3.0 & 3.2 & $4.5\left(^{*}\right)$ & $(-) 0.061$ & $(-) 0.045$ & 0.078 & $0.73(* *)$ \\
\hline $\boldsymbol{C}$ & 1.8 & 1.7 & 2.7 & 0.140 & 0.115 & 0.121 & 0.155 \\
\hline $\boldsymbol{D}$ & 8.2 & 7.0 & 10.0 & 0.078 & 0.051 & 0.098 & 0.064 \\
\hline
\end{tabular}

(-) downward flow

$\left(^{*}\right)$ in Case B both BS model and CFD predict flow reversal (downward), therefore the experimental air temperature for comparison is taken at the bottom of the DSF (at $0.1 \mathrm{~m}$ height)

$(* *)$ the tracer gas method is not reliable when the flow is in reversal, since in such cases the very low concentration of $\mathrm{CO}_{2}$ at the top of the channel can be falsely interpreted as a very high flow rate; this could explain why in Case B the value recorded by the tracer gas instruments would lead to a volume flow rate of $0.73 \mathrm{~m}^{3} / \mathrm{s} / \mathrm{m}$. 
Figure 10 reports temperature maps and streamlines as obtained by CFD, in all four cases considered. It is observed that, as expected, the different pressure and thermal boundary conditions entail completely different predictions of the general flow and temperature patterns in the DSF. In Case A, the wind-induced pressure difference is opposed to buoyancy. Circulation inside the cavity is very weak and limited almost exclusively to the vertical buoyant boundary layers forming along both the internal and external glass. Two recirculation zones are formed at the top and at the bottom of the channel, due to the particular geometry of the two openings, which determine the direction of the entering and exiting jet streams. The temperature rise is high, with a stratification pattern typical of natural convection in vertical cavities.

In Case B, flow reversal is detected, as a consequence of the imposed adverse pressure gradient. Air enters from the top opening, and is directed towards the ceiling of the cavity, where it is deviated downwards, forming a first recirculation. The descending stream is then constrained in the vicinity of the external glass, while the higher temperature of the internal glass causes the appearance of two big recirculation zones alongside it, which correspond to two higher temperature zones. In this case, the temperature rise is moderate.

The high pressure gradient in Case C, combined with the particular thermal conditions, determines an almost isothermal flow, with a very small temperature rise. An ascending jet is formed at the inlet of the façade, and a big recirculating bubble is formed at the bottom right corner. As a consequence of the presence of the window frames, an even bigger vortex is established near the lower part of the external glass. The flow reattaches only at approximately one third of the height of the higher external glazing. Case D is instead characterized by a higher temperature rise, and the combined effect of wind pressure and buoyancy determine a relatively regular ascending flow, with one big recirculation zone forming near the bottom of the cavity.

In Figure 11, computed velocity magnitude profiles and corresponding velocity vectors are displayed alongside the pointwise values recorded by the hot-sphere anemometers installed in the Cube. The profiles are sampled at the heights indicated with roman numbers I-VI in Fig. 3.

It is important to point out that velocity magnitude was chosen for the comparison with the experimental data, due to the fact that the hot-sphere probes are capable of measuring only the velocity magnitude, but 
neither the sole vertical component, nor its sign. As a consequence, from the measured data, it is not possible to recognize the occurrence of recirculation or flow reversals. However, it was shown in Figure 10 that such features are present in all cases, although to different extents. Hence, the addition of velocity vectors to the plot is useful to highlight regions where the predicted velocity magnitude data are associated with recirculating or reversed flow. Another relevant aspect connected to the interpretation of CFD results in light of the experimental data is the sensitivity of the velocity measurements to the position of the sensor, especially in the boundary layer region, which could lead to a higher (albeit unquantifiable) uncertainty of the measured data and, possibly, also to a poorer correspondence with CFD results.

In Case A, where no big recirculation zones are predicted, the numerical profiles exhibit near-wall peaks, typical of natural convection boundary layers, and a stagnant bulk. Velocity vectors are mainly vertical, except for location VI, (slightly higher than the façade outlet), where the flow reverses to reach the DSF opening. Measured data (which are available for locations I-IV only) show a qualitative agreement with the computed ones in the boundary layer region, while non-zero values are present near the cavity center. Such a discrepancy might be ascribed either to the turbulence model, which is likely to overestimate dissipation where the flow is in mixed and transitional conditions, or to three dimensional effects. For this reason, the predicted flow rate in this case is significantly lower than the experimental one (see Table 6). However, the CFD result is still to be regarded as valuable, since it correctly predicts an upward flow as a result of the competition between buoyancy and the adverse pressure gradient, in accordance with the BS model.

In the reversed flow conditions of Case B, many of the computed velocity magnitude profiles are in rather good qualitative agreement with the measured data. Some quantitative correspondences are also remarkable, especially in the boundary layer profiles at all locations (except location V), and in the core flow value at location II. In this case, a comparison between the measured and computed flow rate appears as less significant, not because of the overall downward flow, but instead due to the presence of a high number of recirculation zones. However, it is worthy to mention that, if the flow rate is computed by simply integrating the sampled velocity magnitude values at the anemometer positions (hence, in a similar way to what is actually done with the experimental data), the agreement significantly improves; furthermore, the matching between the flow rates predicted by CFD and the BS model is still fair, indicating that the flow in this 
condition is well represented by CFD, in spite of the shortcomings connected with the adopted modeling choices.

Case C is perhaps the most critical in terms of comparison between CFD and experiments. As shown in Figure 10, in the CFD result, more than half of the cavity height is dominated by a big recirculation which develops along the external glass, The lateral size of this structure affects also the boundary layer at the inner glass, which carries the whole flow rate passing through the façade: as a result, the computed velocity magnitude values are particularly high in that region, and do not match with the experimental values, whereas a better correspondence is observed for what concerns the recirculation zone. These observation suggest that the measured values are compatible with the presence of a recirculation in the lower part of the cavity, whose extent could however be overestimated by the turbulence model. Nevertheless, it is worthy to observe that in case C, the flow is subjected to highly fluctuating wind conditions, and the discrepancy in the results can be ascribed to further reasons. Moreover, a better qualitative agreement is recovered in the upper part of the DSF, and, quite remarkably, the measured and computed flow rates are fairly well aligned (see again Table 6).

Similarly to case A, case D once again exhibits the typical features of a natural convection flow in a wide channel, with a stagnant bulk, in spite of the moderate imposed pressure gradient aiding the flow. Discrepancies in the bulk flow are also present here, even though it is to be observed that the deviation between the computed flow rate and the value measured by means of the tracer gas method is relatively small. Still, it is worthy to point out that the CFD data and the experimental data are locally in good agreement in a number of points, especially in the vicinity of the walls. Furthermore, the profile at location I shows a good quantitative agreement, except for a single point close to the internal wall. By looking at the computed fields, a double recirculation is predicted there, but the measured values might suggest that there could have been only a single recirculation, spanning the right-hand half of the cavity width. Finally, the wind conditions of case D were such that lateral gradients in the DSF could also have been present, determining a non-negligible flow component along the cavity depth, which the present simulations could not take into account. 
Figure 12 reports the trends of bulk temperature as a function of the height $y$, for both the BS and CFD models. Temperature values as measured by the thermocouples at various heights are also plotted, alongside pointwise samples of the CFD results at the cavity centerline, at the same heights, corresponding to the actual position of the probes. External air and measured average glass temperatures are also reported for reference. It is observed that the agreement between the BS and CFD models is remarkable in all cases, as indicated also by the results in Tab. 5 . The experimental data are also in excellent agreement in Case A, whereas in all other cases the modelled bulk temperature profiles seem to underestimate the measured values. However, it is to be noted that the measured value is not always representative of the bulk temperature, but is instead sensitive with respect to the probe position. This is clearly evident when looking at the measured and sampled values near the bottom opening: the measured value is always significantly higher than the bulk temperature value, and so is the sampled one (which, in cases B and C, is in perfect agreement with the measured values). This is due to the particular flow configuration near the bottom of the cavity, where a recirculation is always formed, dragging hot fluid from near the irradiated bottom wall upwards. Some other similar occurrences can be found in the plots.

The remarkable agreement of case $\mathrm{A}$ is due to the almost perfect temperature stratification, which hints at a conduction-dominated heat transfer mode, which matches the horizontal temperature distribution. This is also confirmed by the profiles of the convective coefficient $h_{c v}$, reported in Figure 13 for all cases. These figures highlight the impact of the air velocity on the convective transfer, and, in particular, they indicate that in case A the convective coefficient is nearly constant. It can be observed that the presence of the frames induces local detachments and reattachments of the boundary layers, thus implying strong gradients and local peaks and valleys in the $h_{c v}$ profiles. Moreover, the recirculation forming in the bottom part of the DSF determines a local decrease of the heat transfer coefficient at the internal glass; this is particularly evident for Case D. More generally, the signatures of all the simulated flow features can be recognized in the profiles of $h_{c v}$. As for the hypothesis of constant heat transfer coefficient, only depending on the bulk velocity, made in the BS model, it can be observed that the $h_{c v}$-value is actually only slightly dependent on the flow conditions in the four cases considered, while the CFD analysis shows that both the local flow features and the mean flow rate have an higher impact on the surface heat transfer, and that, for low bulk velocity values, the BS 
model generally overestimates the mean value of the simulated profiles. Coherently enough, the heat removed predicted by the BS model is always higher than the one calculated from the CFD results. Generally speaking, the agreement between the CFD model and experiments can be regarded as good for two types of flow, more specifically for case A and B. On the contrary, in cases C and D the differences are more pronounced, but still there are elements of concordance that talk in favour of the suitability of RANS modeling for the present case. Furthermore, the agreement between the CFD and BS model corroborates the validity of the latter, for what concerns the prediction of bulk flow and heat transfer in the DSF. 

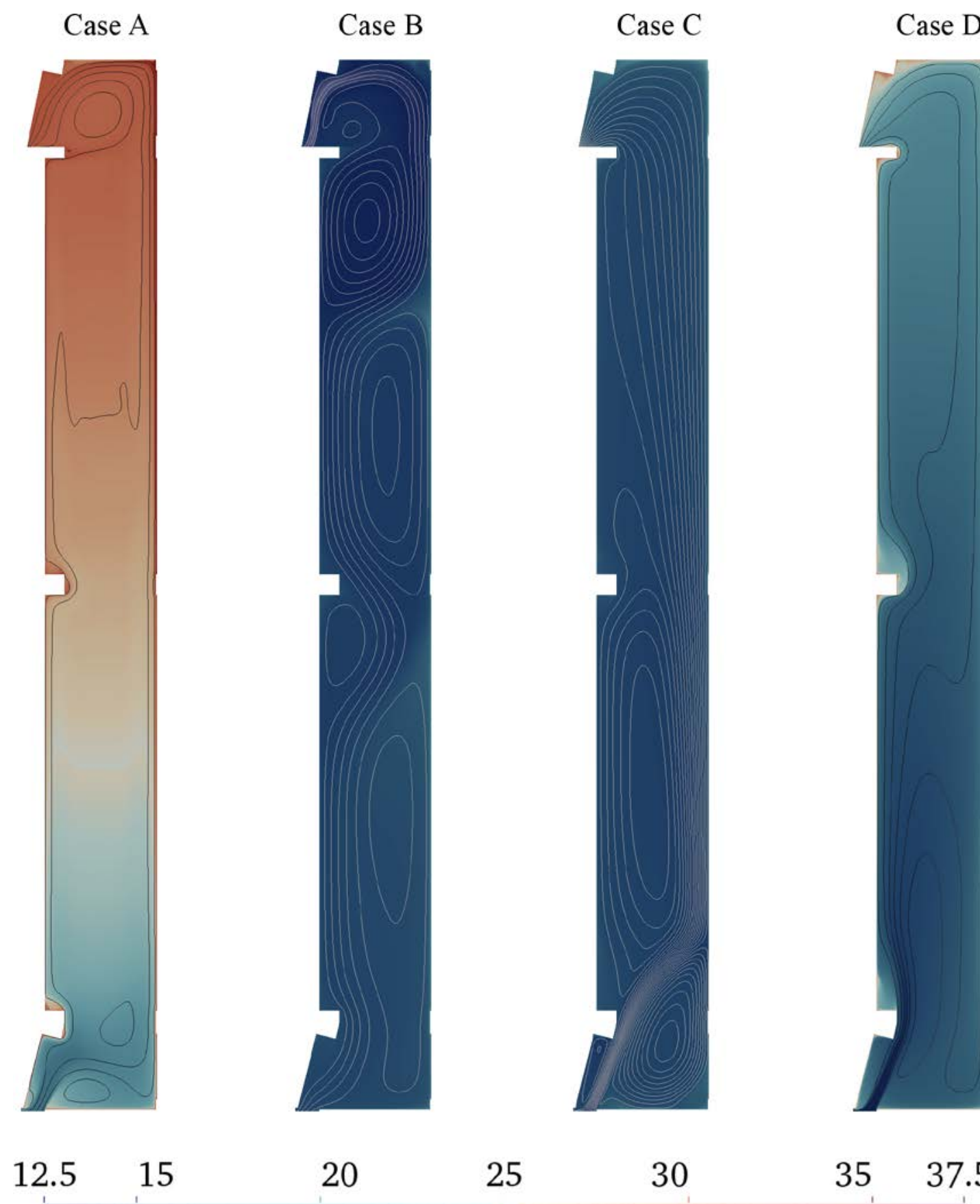

20

25

30

$35 \quad 37.5$

\section{$\mathrm{T}\left[{ }^{\circ} \mathrm{C}\right]$}

Figure 10 - Temperature maps and streamlines as obtained by CFD for all four simulated cases. 
Case A
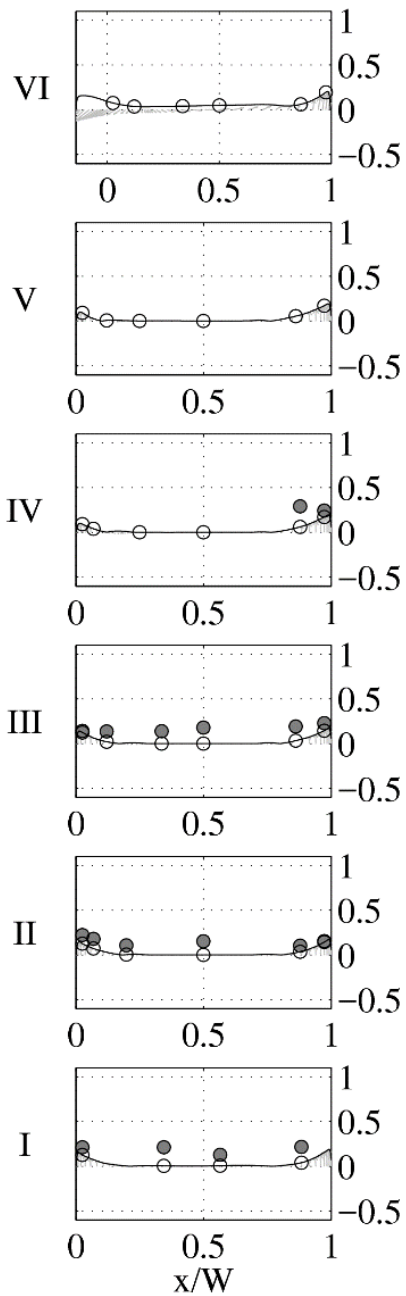

Case B
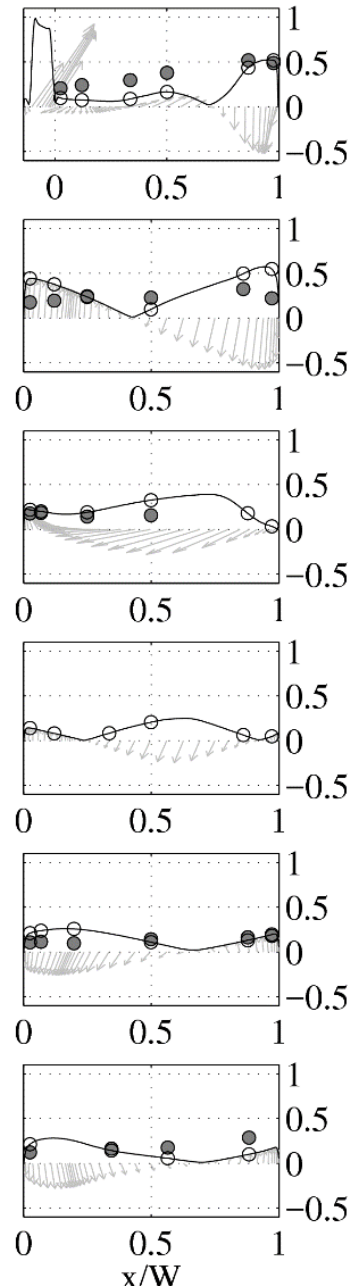

Case $\mathrm{C}$
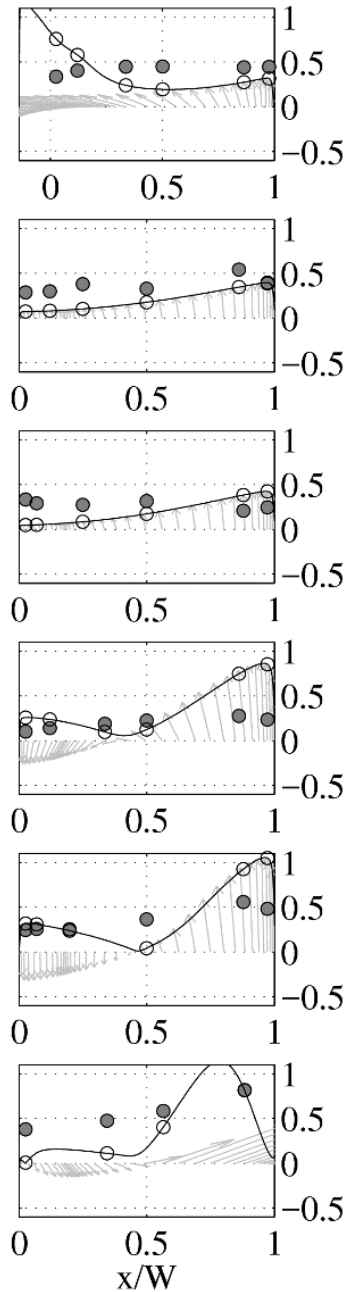

Case D
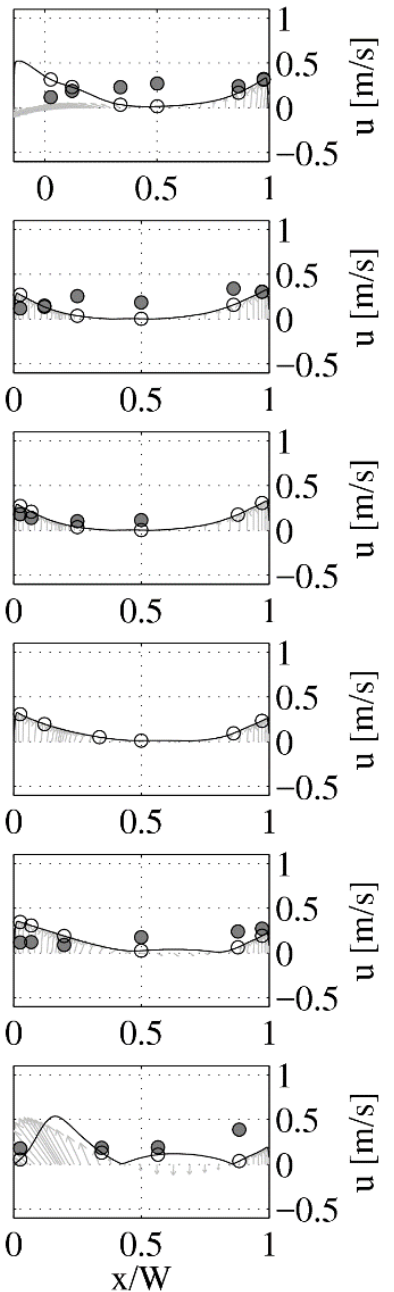

Figure 11 - Profiles of velocity magnitude (hollow circles and lines) and velocity vectors as computed by

CFD, and velocity values measured by hot-sphere anemometers (grey circles), for all the four cases simulated cases and for all the anemometers installation heights (see Figure 3). The horizontal coordinate is normalized by the cavity width $\mathrm{H}$ for the sake of clarity 
Case A

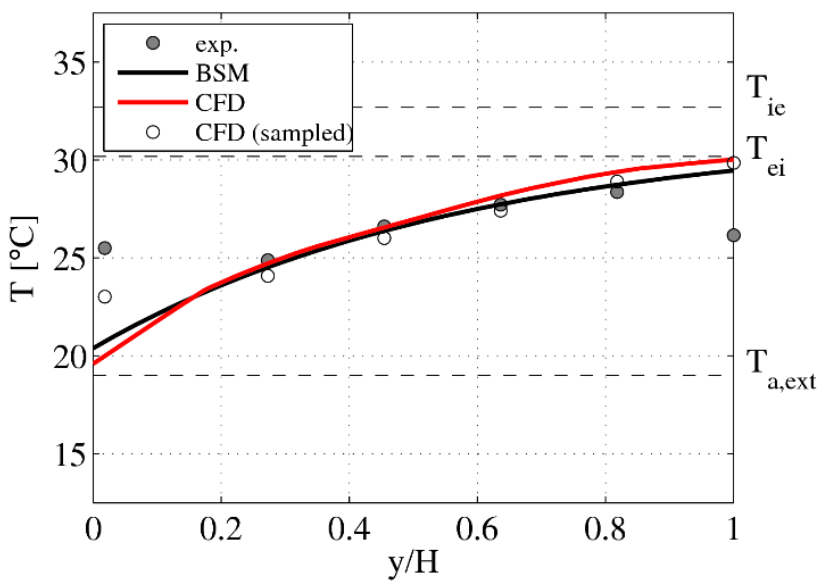

Case C

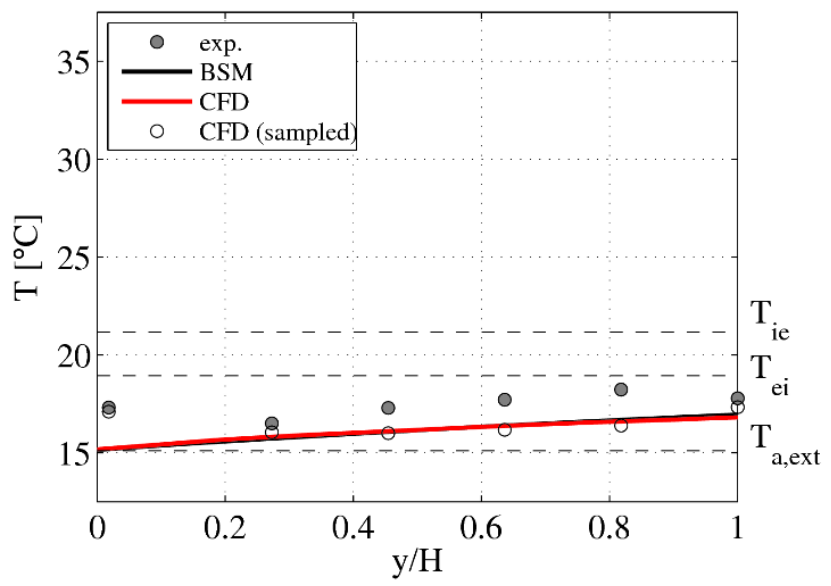

Case B

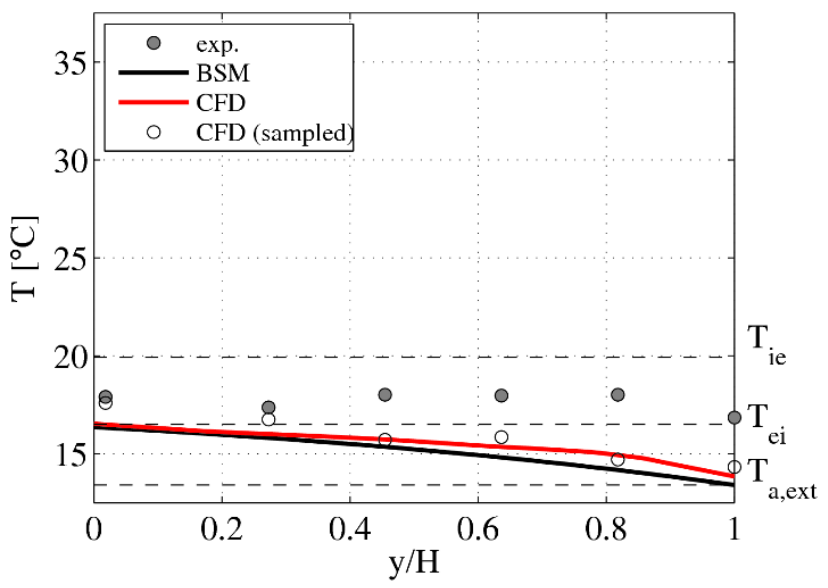

Case D

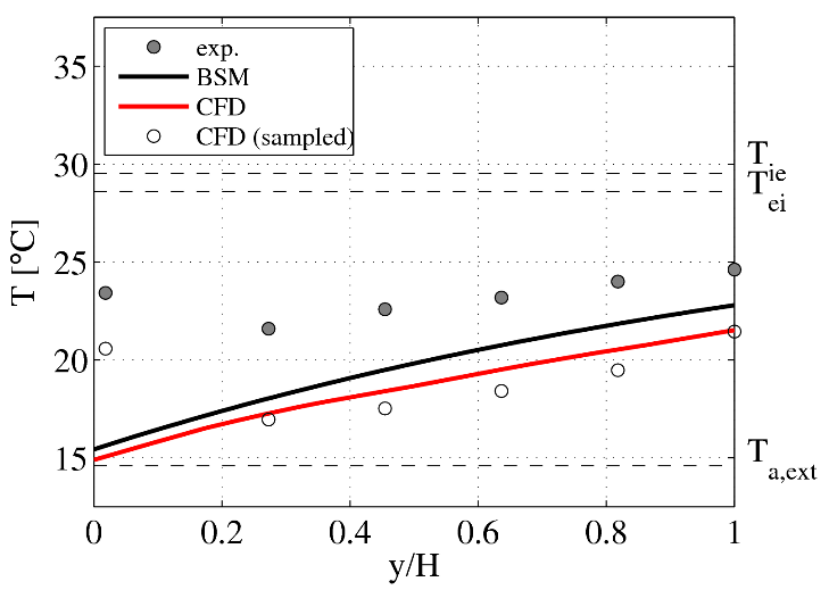

Figure 12 Vertical profiles of bulk temperature for all the four cases analyzed by CFD, as compared measurements and outcomes of the BS model. The vertical coordinate is normalized by the cavity height $\mathrm{H}$ for the sake of clarity. Local samples of the computed temperature fields at one half of the cavity width are also added to the plot, at heights corresponding to the position of shielded termocouples. 
Case A

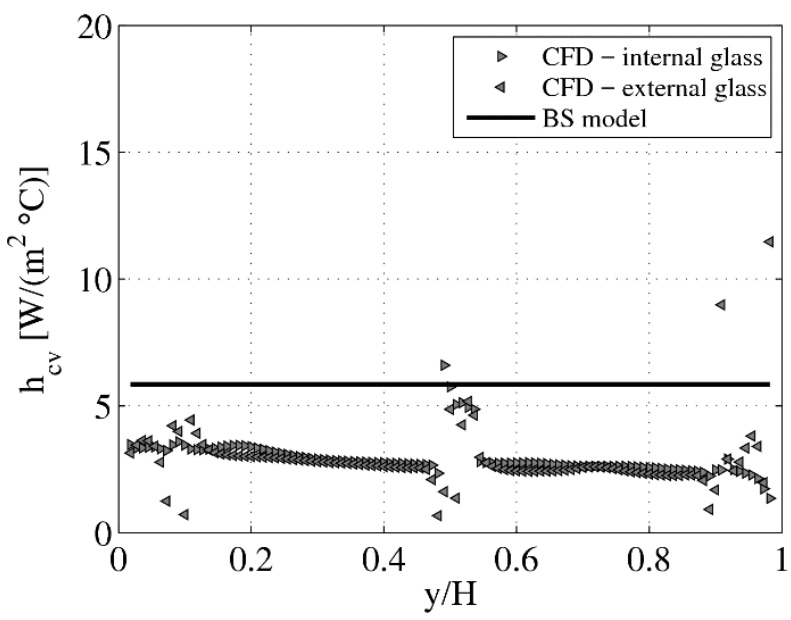

Case C

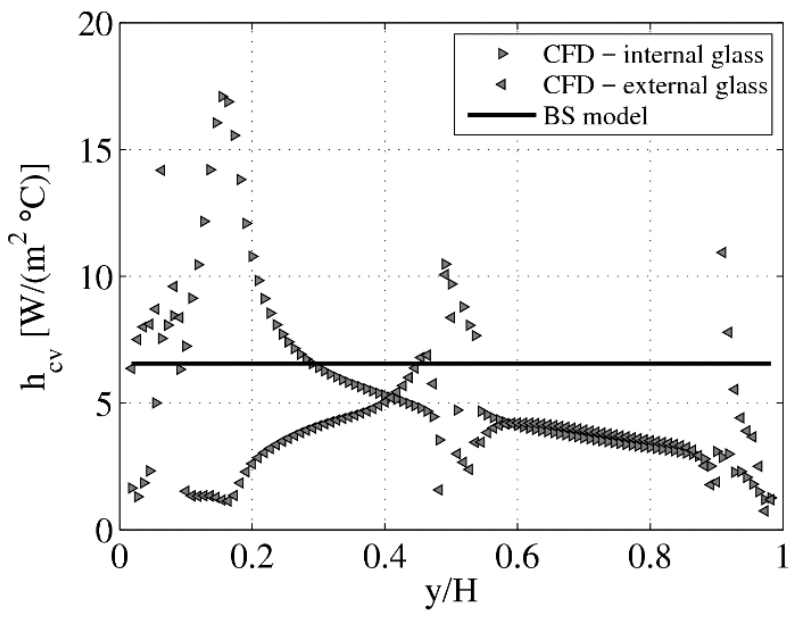

Case B

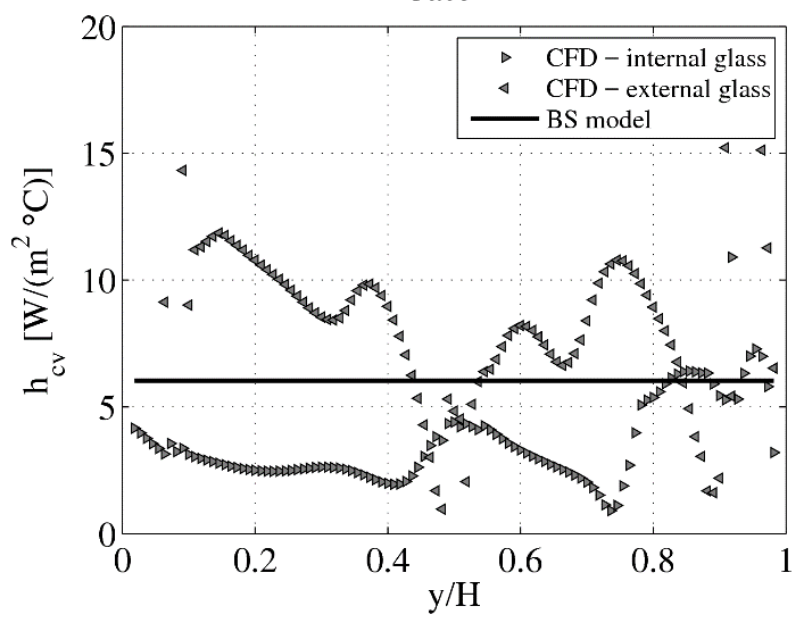

Case D

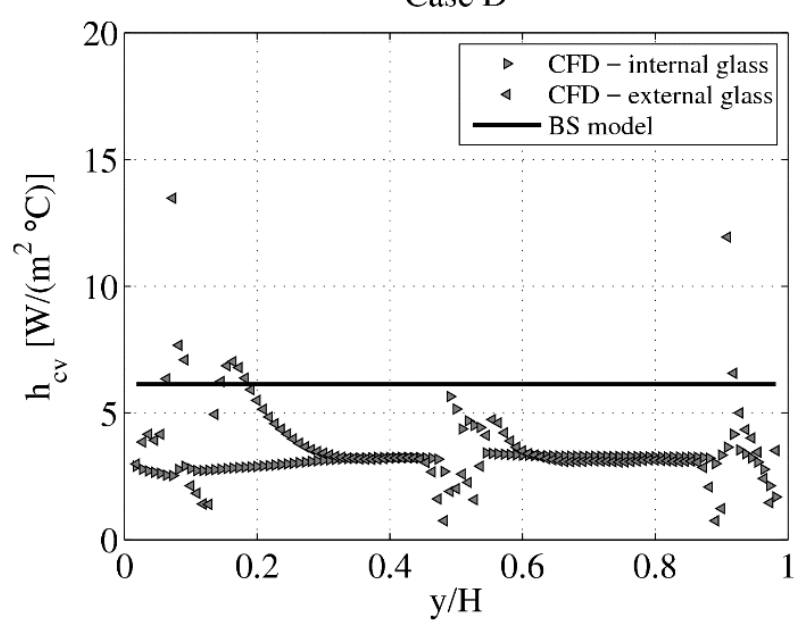

Figure 13 - Profiles of the heat flux along the external and internal glass for all the simulated cases, as obtained by CFD, compared with the value computed by the BS model. 


\section{Conclusions}

The development of rapid, robust and accurate tools for performance evaluation of naturally ventilated double-skin façade constructions is seen as an ultimate goal for the building physics research community and, more generally, the civil industry. Naturally induced airflow in double-skin façade cavities, however, is one of the most sensitive features of this kind of system, for which the thermal and mass balance of the system remain difficult to predict.

The present work considered a naturally ventilated cavity, for which three different methodologies, significantly different in their principle and complexity, are employed in order to come one step closer to the aforementioned goal. These are:

- A thermal model suitable for integration in building simulation, named BS model

- $\quad$ A 2D Computational fluid dynamics model

- A full-scale experimental study on a DSF test facility, and the resulting database of field and pointwise airflow and temperature measurements spanning a total of 15 days of continuous operation.

The overall objective of this study was first of all to validate the BS model experimentally, and more specifically to examine and validate the prediction of the wind and total differential pressure at the openings, which has never been done before for DSF constructions, and only to a limited extent for naturally ventilated spaces. The results show that the simple BS model presents a good level of agreement with the experimental data in predicting the mass flow rate and the heat removed by ventilation, despite the high complexity of the flow in the gap, fluctuating boundary conditions and frequent flow reversal. Although the two experimental methods used to determine the airflow rate in the DSF cavity produce in many cases divergent results, it was possible to distinguish valid experimental results for comparison with the BS model. This was possible thanks to a thorough analysis of the experimental procedure together with the insight provided by the model into the determination of the driving wind and thermal differential pressures.

Considering the heat removed by ventilation integrated on daily basis and comparing the model results with the experimental data source (tracer gas versus velocity profile method), which, from case to case, was 
judged as more reliable, the relative errors of the model predictions are less than $12 \%$ for eight of the fifteen days of the experimental campaign, while in the other days the underestimations do not exceed $-32 \%$, a result which can still be considered acceptable in this field. Moreover, by selecting only the measurements associated to sufficiently low wind fluctuations in the hourly averaged data, a good degree of correlation was found between the predicted total driving pressure and the flow measurements, and a very good agreement arises between the modelled equivalent discharge coefficient and the flow measurements with the velocity profile method.

Undoubtedly, the performance of the BS model can be questioned for specific complex flow conditions in the gap, as those are not resolved by the model. This, however, can be improved if more insight into the flow conditions and their impact on overall performance of the system is documented.

The second part of this work was dedicated to a 2D CFD U-RANS analysis of four selected time instances extracted from the experimental database. CFD results provided an insight in the variety of flow conditions which can be encountered in the cavity, resulting in significantly different temperature distributions across the domain, wide spread of local recirculation patterns, and many other distinctive flow features. In particular, the comparison between measured and computed airflow and temperature data made it possible to draw a realistic picture of the DSF performance, as obtained with a rather accessible 2D CFD model. Speaking of the results on a quantitative scale, some deviations from the measurement data are present. These, however, do not disrupt the overall, qualitative picture of the realistic flow, given the limitations of the CFD approach employed, in terms of turbulence modeling, and deviation between actual and assumed boundary conditions. Particularly noticeable is the good quantitative agreement between the CFD model and experiments for the entrance flow in all of the tested scenarios. Moreover, for all four cases selected, the agreement between the BS and CFD models is remarkable in terms of outlet temperatures and in the prediction of flow reversal. Further developments within this scope would imply the adoption of more refined turbulence modeling approaches and full-scale simulations of the entire facility subjected to an incoming wind and to solar irradiation.

As a final remark, it can be concluded that the BS model presented here, completed by a correct modeling of the wind effect, represents a quantitatively reliable tool for the prediction of the overall performance of a 
naturally-ventilated DSF, while RANS CFD, under well-posed boundary conditions, can provide a useful insight to the expert designer on the possible flow configurations occurring in the cavity, thus driving the detail design of the façade itself.

\section{Acknowledgement}

The authors acknowledge the networking opportunities given by the Cost Action TU1403 “Adaptive Façades Network”.

\section{References}

[1] D.M.M. Arons, L.R. Glicksman, Double Skin, Airflow Façades: will the Popular European Model work in the USA?, in: Proc. ICBEST 2001, Int. Conf. Build. Envel. Syst. Technol., FINVAC ry, Ottawa, Canada, 2001: p. 203.207.

[2] D. Saelens, Energy Performance Assesment of Single Storey Multiple-Skin Façades. PhD Thesis., Katholieke Universiteit Leuven, 2002.

[3] K. Gertis, A critical review of Double Glazing Façades Under Aspects of Building Physics, Ger. J. Bauphysik. 21 (1999) 54-66.

[4] O. Kalyanova, P. Heiselberg, Empirical Validation of Building Simulation Software : Modeling of Double Façades, (2008).

[5] O. Kalyanova, P. Heiselberg, C. Felsmann, H. Poirazis, P. Strachan, A. Wijsman, An Empirical Validation of Building Simulation Software for Modelling of Double-Skin Façade (DSF), in: Build. Simul. 2009 Proc. 11th Int. Build. Perform. Simul. Assoc. Conf., University of Strathclyde, Glasgow, 2009.

[6] N. Mingotti, T. Chenvidyakarn, A.W. Woods, The fluid mechanics of the natural ventilation of a 
narrow-cavity double-skin façade, Build. Environ. 46 (2011) 807-823.

doi:10.1016/j.buildenv.2010.09.015.

[7] P. Seferis, P. Strachan, A. Dimoudi, A. Androutsopoulos, Investigation of the performance of a ventilated wall, Energy Build. 43 (2011) 2167-2178. doi:10.1016/j.enbuild.2011.04.023.

[8] H. Manz, T. Frank, Thermal simulation of buildings with double-skin façades, Energy Build. 37 (2005) 1114-1121. doi:10.1016/j.enbuild.2005.06.014.

[9] S. Barbosa, K. Ip, Perspectives of double skin façades for naturally ventilated buildings: A review, Renew. Sustain. Energy Rev. 40 (2014) 1019-1029. doi:10.1016/j.rser.2014.07.192.

[10] A. Angelotti, A. Dama, L. Mazzarella“Modeling naturally ventilated double skin façades, Proceedings of CLIMA 2010 - 10th REHVA World Congress "Sustainable Energy Use in Buildings", Antalya, Turkey, May 9-12, 2010.

[11] D. Angeli, A. Dama “Modelling natural ventilation in double skin façade”, Energy Procedia, November 2015, Volume 78, Pages 1537-1542

[12] A. Dama, D. Angeli ”Wind and buoyancy driven natural ventilation in double skin façades” International Journal of Ventilation, (2016) Vol.15, Issue 3-4, pg. 288-301

[13] O.K. Larsen, P. Heiselberg, R.L. Jensen, Experimental data and boundary conditions for a DoubleSkin Façade building in external air curtain mode, (2014).

[14] O.K. Larsen, F. Zanghirella, P. Heiselberg, M. Perino, R.L. Jensen, Measuring Air Temperature in Glazed Ventilated Façades in the Presence of Direct Solar Radiation, Int. Conf. Air Distrib. Rooms, Roomvent. (2007).

[15] O.K. Larsen, R.L. Jensen, P. Heiselberg, Measurement of Air Flow Rate in a Naturally Ventilated Double Skin Façade, Int. Conf. Air Distrib. Rooms, Roomvent. (2007).

[16] R.L. Jensen, O.K. Larsen, C.-E. Hyldgård, On the Use of Hot-Sphere Anemometers in a Highly 
Transient Flow in a Double-Skin Façade, Int. Conf. Air Distrib. Rooms, Roomvent. (2007).

[17] D. (David W.. Etheridge, M. Sandberg, Building ventilation : theory and measurement, John Wiley \& Sons, 1996.

[18] J. Mcwilliams, Review of Airflow Measurement Techniques, (2002).

[19] D. Saelens, S. Roels, H. Hens “The inlet temperature as a boundary condition for multiple-skin façade modelling”, Energy and Buildings, 2004.vol. 36, pp. 825-83.

[20] http://www.wind.arch.t-kougei.ac.jp/system/eng/contents/code/tpu

[21] AIJ Recommendations for Loads on Buildings (in Japanese), Architectural Institute of Japan (2004)

[22] H.G. Weller, G. Tabor, H. Jasak, C. Fureby “A tensorial approach to computational continuum mechanics using object orientated techniques”, Comp. Phys., 1998, 12:620-631.

[23] D.D. Gray, A. Giorgini “The validity of the Boussinesq approximation for liquids and gases”, Int. J. Heat Mass Transfer, 1976, 19:545-551.

[24] F.R. Menter “Two-Equation Eddy-Viscosity Turbulence Models for Engineering Applications”, AIAA Journal, 1994, Vol. 32, no 8. pp. 1598-1605.

[25] S.V. Patankar "Numerical Heat Transfer and Fluid Flow”, 1st ed. Hemisphere, Washington DC, 1980.

[26] R. Issa "Solution of the Implicit Discretized Fluid Flow Equations by Operator Splitting”, J. Comp. Phys., 1985, 62:40-65. 